\title{
Esthetic smile rehabilitation of anterior teeth by treatment with biomimetic restorative materials: a case report
}

\author{
Thayla Hellen Nunes \\ Gouveia \\ Jéssica Dias Theobaldo \\ Waldemir Francisco \\ Vieira-Junior \\ Débora Alves Nunes Leite \\ Lima \\ Flávio Henrique Baggio \\ Aguiar
}

Department of Restorative Dentistry, Piracicaba Dental School, University of Campinas, Campinas, SP, Brazil
This article was published in the following Dove Press journal:

Clinical, Cosmetic and Investigational Dentistry

II May 2017

Number of times this article has been viewed

Background: In daily clinical practice, esthetics of anterior teeth is a common presenting complaint of patients.

Objective: This case report discusses the management of asymmetric smile associated with unsatisfactory extensive composite restorations and describes a clinical protocol using the direct composite resin for smile enhancement to restore the dental harmony of anterior teeth.

Methods: The treatment planning was based on a diagnostic wax-up and cosmetic mock-up. After clinical and patient approvals were obtained, the patient was subjected to direct and indirect restorative treatment.

Conclusion: Nanocomposites are an effective alternative for anterior teeth restorations. Additionally, good planning enables satisfactory esthetic results, leading to the correction of an inappropriate axial inclination of incisors.

Keywords: composite, adhesive, smile, esthetic, restoration

\section{Introduction}

The demand for esthetic dentistry has extensively increased; thus, treatment protocols for reestablishment of a smile have been proposed aiming at well-aligned and wellcontoured teeth, setting the standard for beauty. ${ }^{1,2}$ In this sense, the beauty of smile is a correlation between teeth, gingiva, and lips. ${ }^{3}$ In daily clinical practice, esthetics of anterior teeth is a common presenting complaint of patients, which is affected by caries, malformation, anatomic alteration, discoloration/staining, and hypoplastic defects. ${ }^{2}$

Esthetic dentistry involves a harmonious integration of material selection and smile rehabilitation. ${ }^{4}$ In relation to treatment of anterior teeth, the maxillary central incisors are the visual focal point for the smile, thus they should be symmetrical and dominant. ${ }^{4,5}$ The best approach to anterior teeth treatment has been widely discussed and a number of clinical protocols have been reported..$^{2-4}$ Among these, the all-ceramic or metal-ceramic crowns stand out due to their high biocompatibility, color stability, high abrasion resistance, and clinical efficacy. ${ }^{6,7}$ Therefore, indirect treatments lead to excessive preparations of teeth and damages to surrounding tissues, such as gingival, ${ }^{8}$ and ceramic can be abrasive for the natural tooth structure. ${ }^{9}$ Thus, the restorative treatment with resin composite promotes a conservative dramatic esthetic change in a single appointment. ${ }^{10,11}$ Direct resin materials are the materials of first choice to restore anterior and posterior teeth. ${ }^{11,12}$

The present case report discusses the management of asymmetric smile associated with unsatisfactory extensive composite restorations and describes a clinical protocol
Correspondence: Flávio Henrique Baggio Aguiar

Department of Restorative Dentistry, Piracicaba Dental School, PO Box 52, University of Campinas - UNICAMP, |34|4-I3903, Piracicaba, SP, Brazil Tel+55192101 5340 Email aguiar@fop.unicamp.br 
using the direct composite resin for smile enhancement to restore the dental harmony of the anterior teeth.

\section{Case presentation}

A 50-year-old female patient presented at the Piracicaba Dental School (University of Campinas, Piracicaba, São Paulo, Brazil) with the complaint of smile dissatisfaction relating to the inverted appearance of the anterior teeth (Figure 1).

The clinical examination revealed extensive direct restorations in the anterior teeth with unsatisfactory color, roughened texture, and inappropriate axial inclination of incisors. On radiographic examination and pulp vitality test, the teeth showed vitality, with no signs of periodontal injuries (Figure 2).

As part of the examination, an impression was made using a polyvinyl siloxane material (Express ${ }^{\mathrm{TM}}$ XT; 3M ESPE, St Paul, MN, USA) for the reproduction of plaster models. Then, the dental esthetic planning was performed and used as a reference for the realization of wax-up diagnostic by the progressive technique with wax type II (Asfer, São Paulo, Brazil; Figure 3A).

A silicone guide was obtained from the wax model of the new dental anatomy. The silicone buildup guide was used to provide a mock-up with a bis-acrylic resin (PROTEMP TM 4, 3M ESPE). This mock-up is adapted in the mouth of patient (Figure 3B). After finishing the mock-up, esthetic and functional tests were performed. The case was accomplished with direct restorative treatment (units: 13, 12, 11, 21, and 22) after obtaining clinical and patient approval (Figure 4). The indirect restorations in units 14 and 23 were replaced for all-ceramic crowns (lithium disilicate ceramic: IPS e.max CAD; Ivoclar Vivadent AG, Schaan, Lichtenstein).

Units (14-24) were isolated, and the existing restorations were removed with a spherical diamond bur \#1014 (KG Sorensen, Barueri, Brazil; Figure 4A and B). After teeth preparation, a retraction cord (Ultradent, Indaiatuba, Brazil) was used to ensure dryness of the gingival sulcus and to promote gingival retraction to view the margin of restoration (Figure 4C). The enamel and dentin surfaces were treated with $35 \%$ phosphoric acid gel (Ultradent) for 30 and 15 seconds, respectively (Figure 4D). The phosphoric acid was rinsed for 30 seconds and the excess water was removed with cotton

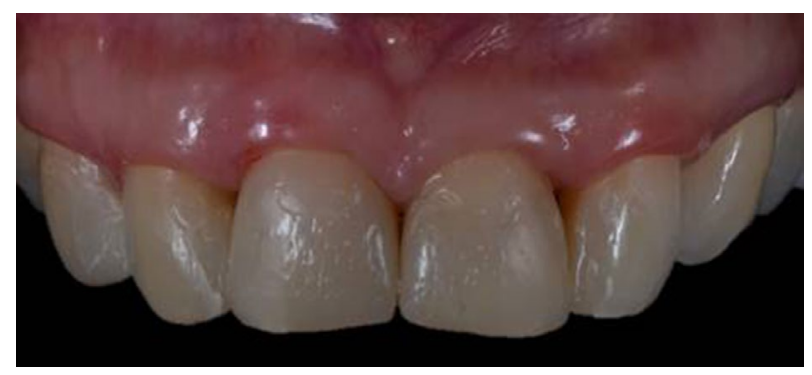

Figure 2 Initial case showing extensive restoration in the anterior teeth and inappropriate axial inclination of the incisors, which is considered as essential for smile esthetics.

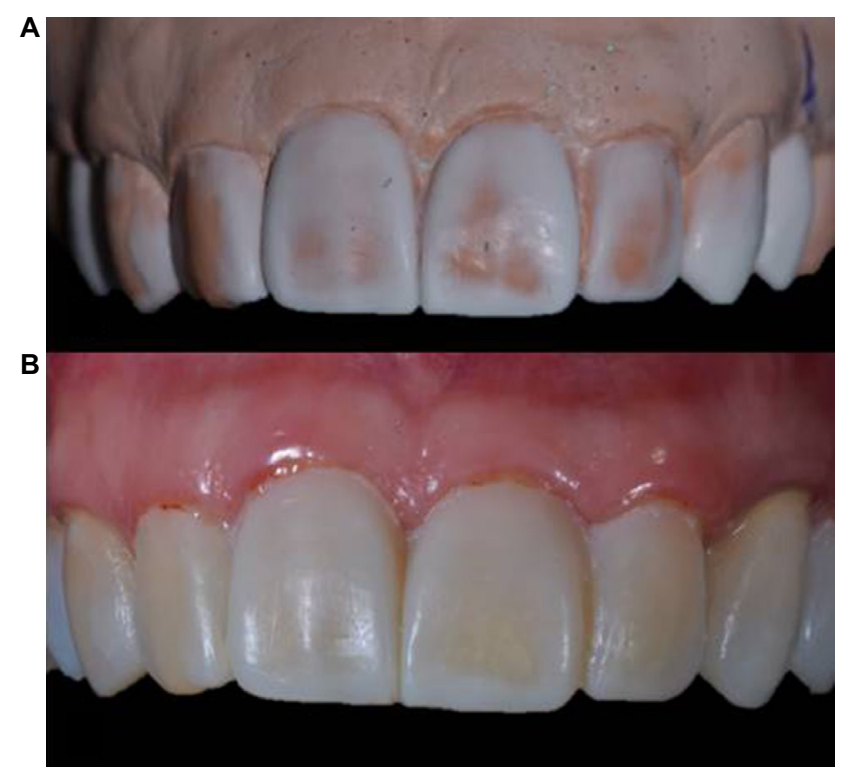

Figure 3 (A) Diagnostic wax-up; and (B) cosmetic mock-up.

pellets (Figure 4E and F). A two-step etch-and-rinse adhesive Adper Single Bond 2 (3M ESPE) was applied according to the manufacturer's recommendations (Figure $4 \mathrm{G}$ and $\mathrm{H}$ ).

The silicone barrier was positioned to reproduce the palatal portion of the teeth (Figure 4I) with a thin layer of a nanocomposite (WE-Filtek Z350 XT ${ }^{\circledR}$, 3M ESPE; Figure 4J and $\mathrm{K}$ ). The body resin shade A2B (Filtek Z350 XT, 3M ESPE) was used to reproduce the dentin tissue (Figure $4 \mathrm{~L}$ ). Finally, WE-Filtek Z350 XT resin was reapplied, filling all the restored surfaces (Figure 4M). Texturizing and finishing were carried out with fine and extra-fine diamond burs and sof-lex discs (3M ESPE). Then, polishing was performed using a felt

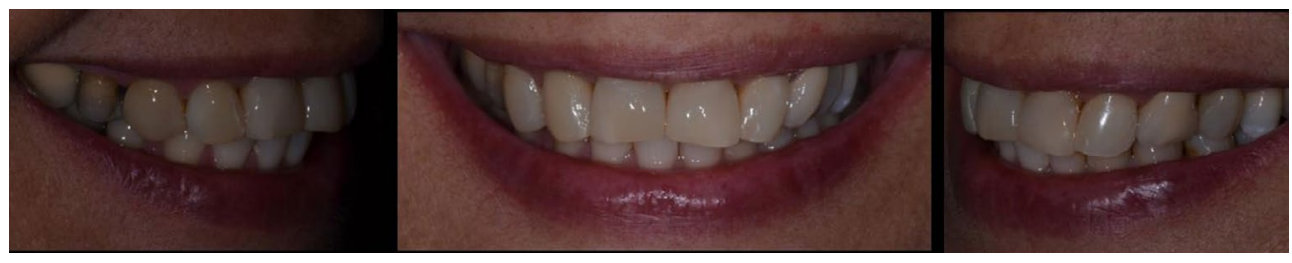

Figure I Initial smile showing the inverted smile arc. 


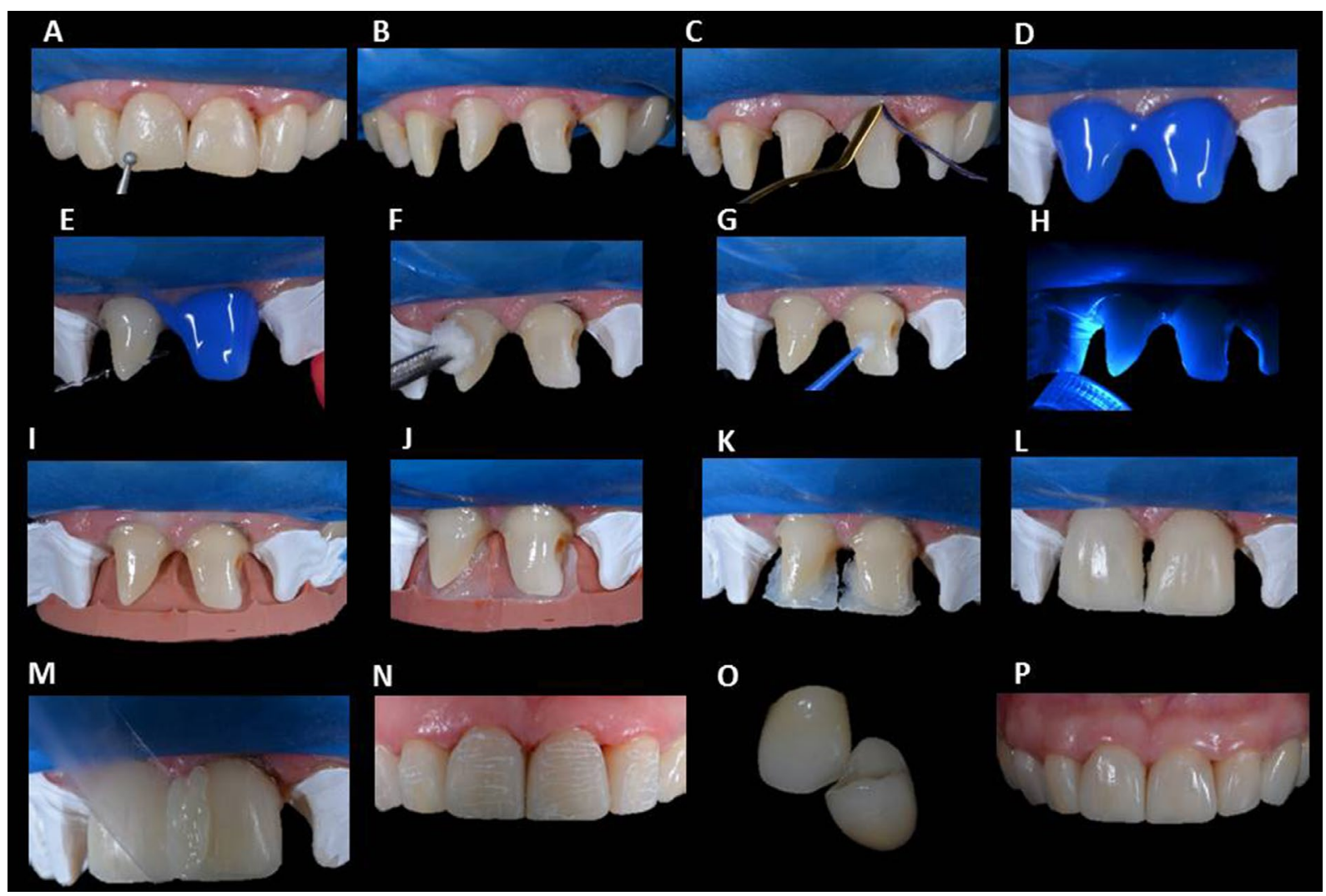

Figure 4 Clinical sequence of procedures.

Notes: (A) Removal of unsatisfactory restorations using a diamond bur; (B) dental substrate after removal of resin composite; (C) installation of nonimpregnated gingival retraction cord; (D) acid etching of the enamel for 30 seconds and dentin for 15 seconds (35\% phosphoric acid); (E) rinsing for 30 seconds; (F) drying with slightly damp cotton aiming at humidity control of dental substrate; (G) Adper Single Bond 2 (3M ESPE) layer was applied according to manufacturer's instructions; (H) adhesive system light-cured for 20 seconds; (I) The adaptation of silicone guide was checked to perform the restoration of the palatal face; (J, K) composite resin increment first inserted in palatal face; (L) resin composite increments simulating the dentin; $(\mathbf{M})$ surface resin composite increments simulating the enamel; $(\mathbf{N})$ anatomical characterization of restoration with fine diamond bur; (O) all-ceramic crowns in units 14 and 23; (P) final restorations after finishing and polishing of resin composites.

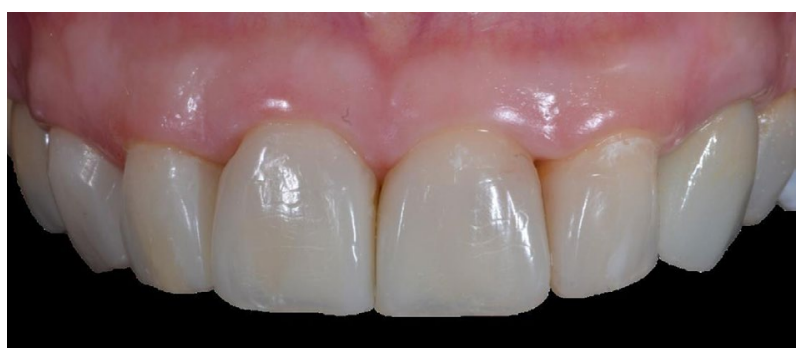

Figure 5 Final case.

Note: Appropriate axial inclination of the incisors which is considered as essentia for smile esthetics. polishing cloth associated with diamond pastes (Enemalize; Cosmedent, Chicago, IL, USA; Figure 4N). After finalization of the direct restorative procedures, a resin luting cement (Rely-X Arc, 3M ESPE) was used for cementing all-ceramic crowns (Figure 4O). Figures 4 and 5 demonstrate the final aspect of the restorative treatment.

Figure 6 shows the harmonious smile, with an appropriate relationship between the teeth, gingiva, and lips, which are fundamental factors to restore the harmony and the natural smile.

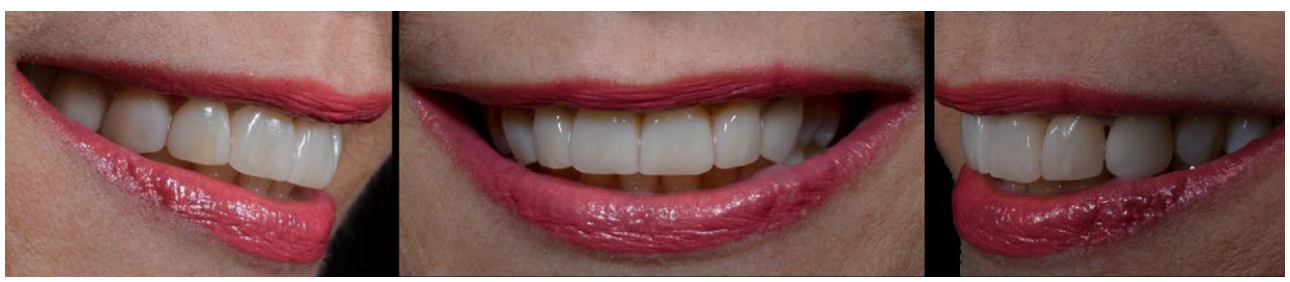

Figure 6 Final smile.

Note: Predominance of central incisors and the correction at inverted smile arc. 


\section{Discussion}

This case study assessed the replacement of extensive restorations presenting color alteration and inappropriate roughness, as well as the correction of incisors' axial inclination (Figure 1). Treatment of vital teeth was carried out using wax-up, mock-up (Figure 3A and B), and radiographic/clinical examination. Thus, a conservative approach was used for the restoration using a nanocomposite resin for direct technique restoration, maintaining the vitality and structure of the tooth. Although it is a technique that requires a significant amount of chair time, direct composite resin is a less-expensive treatment than ceramic veneers and is more accessible to the patient. In addition, composite resin is a material that has a good performance and increases the longevity of treatment. ${ }^{10}$

The restorative material should have physical and mechanical properties similar to tooth structure for achieving clinical success. ${ }^{13}$ Nanocomposites have a high mechanical resistance to fracture and wear, lower polymerization shrinkage, excellent polishing, color stability, and good optical properties such as fluorescence and translucency, and are safely indicated for restorations of anterior and posterior teeth. ${ }^{14-17}$ The nanocomposite Filtek Z350 XT is composed of silica nanoparticles and silane-coated zirconia prior to incorporation into the resin matrix (manufacturer's information). Due to the small-sized filler particles, a larger amount can be inserted into the resin matrix, providing excellent physical and mechanical properties of the material. ${ }^{14}$

The layering technique using composite resin is the most indicated for anterior teeth. This technique aims to enable complete light-curing of resin increment and to reduce the volume of contracting material, thus mitigating polymerization shrinkage stresses. ${ }^{18,19}$ Polishing of the resin composite surface is another clinical step, which is very important for color stability. ${ }^{20}$ Moreover, alteration of surface roughness is an important factor for bacterial adhesion and plaque accumulation. ${ }^{21-23} \mathrm{~A}$ well-polished resinous surface prevents bacterial adhesion and decreases the biofilm formation, reducing the risk of secondary caries. According to Chour et al, polishing techniques using sof-lex and diamond paste can be used to remove rough areas, increasing the longevity of restorations. ${ }^{22}$

The adhesive process is highly sensitive and its success is directly related to the correct application of the material and the clinical technique. ${ }^{24}$ Several factors can affect the longevity of restoration, including the type of substrate, location and size of the restoration, reasons for restoration, restorative material, and restoration conditions. In this context, absolute isolation is the most indicated procedure (Figure 4A-M). ${ }^{25,26}$
Secondary caries or fracture is the most common cause of failure of posterior adhesive restorations. ${ }^{27,28}$ Nevertheless, in anterior composite resin restorations, fracture of the tooth or restoration is the most frequent cause of failure. In anterior teeth, Class IV restorations involving the incisal edge are subjected to high-level masticatory loads, with fracture as a possible clinical outcome over time..$^{29,30}$ As reported by Alonso and Caserio, the failures more related to esthetic restorations were color alterations, surface staining, and marginal mismatch that can negatively influence the patient's perception of the restoration. ${ }^{31}$

Up to date, it is possible to find systematic reviews and meta-analysis about the longevity of anterior restorations. ${ }^{10,32}$ The findings indicate a good clinical performance in the long term (follow-up 3+ years) for anterior composite resin restorations, with annual failure rates from $0 \%$ to $4.1 \%$. According to a study by Frese et al, direct composite restoration is indicated for noninvasive or minimally invasive treatment because the follow-up of the restorations showed a functional survival rate of $100 \%$, with an overall survival rate of $84.6 \%$ after 5 years. ${ }^{33}$ The failure behavior in anterior restorations is different from that observed in posterior teeth, with less secondary caries present and more restorations being replaced for other reasons, including esthetic appearance. ${ }^{10,32}$

The advances in dental materials in recent years have revolutionized the concepts applied to restorative dentistry, making it basically an adhesive dentistry. The development of resinous materials and adhesive systems allows minimally invasive procedures and highly esthetic restorations, preserving a greater amount of dental tissue, which is highly advantageous. Therefore, it is possible to conclude that nanocomposite resins can be indicated for anterior teeth restorations, as they demonstrate good optical and mechanical properties. Furthermore, the resin composite restorations promote an effective long-term performance.

\section{Conclusion}

Nanocomposites are an effective alternative for anterior teeth restorations. Additionally, good planning enables satisfactory esthetic results, leading to the correction of an inappropriate axial inclination of incisors.

\section{Acknowledgment}

The authors acknowledge the patient who provided written informed consent to allow this case report to be published along with the accompanying images.

\section{Disclosure}

The authors report no conflicts of interest in this work. 


\section{References}

1. Chou JC, Nelson A, Katwal D, Elathamna EN, Durski MT. Effect of smile index and incisal edge position on perception of attractiveness in different age groups. J Oral Rehabil. 2016;43(11):855-862.

2. Moskowitz ME, Nayyar A. Determinants of dental esthetics: a rational for smile analysis and treatment. Compend Contin Educ Dent. 1995;16(12):1164-1166.

3. Garber DA, Salama MA. The aesthetic smile: diagnosis and treatment. Periodontol 2000. 1996;11:18-28.

4. Marus, R. Treatment planning and smile design using composite resin. Pract Proced Aesthet Dent. 2006;18(4):235-241.

5. Wolfart S, Thormann H, Freitag S, Kern M. Assessment of dental appearance following changes in incisor proportions. Eur J Oral Sci. 2005;113(2):159-165.

6. Nazirkar G, Meshram S. An evaluation of two modern all-ceramic crowns and their comparison with metal ceramic crowns in terms of the translucency and fracture strength. Int J Dent Clin. 2011;3(1):5-7.

7. Donovan TE. Factors essential for successful all-ceramic restorations. J Am Dent Assoc. 2008;139 Suppl:14S-18S

8. Korkut B, Yanıkoğlu F, Günday M. Direct composite laminate veneers: three case reports. J Dent Res Dent Clin Dent Prospects. 2013;7(2):105-111.

9. Dahl BL, Carlsson GE, Ekfeldt A. Occlusal wear of teeth and restorative materials.A review of classification, etiology, mechanisms of wear, and some aspects of restorative procedures. Acta Odontol Scand. 1993;51(5):299-311.

10. Demarco FF, Collares K, Coelho-de-Souza FH, et al. Anterior composite restorations: a systematic review on long-term survival and reasons for failure. Dent Mater. 2015;31(10):1214-1224.

11. Demarco FF, Baldissera RA, Madruga FC, et al. Anterior composite restorations in clinical practice: findings from a survey with general dental practitioners. J Appl Oral Sci. 2013;21(6):497-504.

12. Baldissera RA, Corrêa MB, Schuch HS, et al. Are there universal restorative composites for anterior and posterior teeth? J Dent. 2013;41(11):1027-1035.

13. Summitt JB, Robbins JW, Schwartz RS. Fundamental of Operative Dentistry: A Contemporary Approach. Carol Stream, IL: Quintessence Publishing; 2001.

14. Ferracane JL. Resin composite-state of the art. Dent Mater. 2011; 27(1):29-38.

15. Tanimoto Y, Hirayama S, Yamaguchi M, Nishiwaki T. Static and dynamic moduli of posterior dental resin composites under compressive loading. J Mech Behav Biomed Mater. 2011;4(7):1531-1539.

16. Chen MH. Update on dental nanocomposites. J Dent Res. 2010; 89(6):549-560.

17. Curtis AR, Palin WM, Fleming GJ, Shortall AC, Marquis PM. The mechanical properties of nanofilled resin-based composites: the impact of dry and wet cyclic pre-loading on bi-axial flexure strength. Dent Mater. 2009;25(2):188-197.
18. Liebenberg WH. Successive cusp build-up: an improved placement technique for posterior direct resin restorations. J Can Dent Assoc. 1996; 62(6):501-507.

19. Deliperi S, Bardwell DN. An alternative method to reduce polymerization shrinkage in direct posterior composite restorations. $J$ Am Dent Assoc. 2002;133(10):1387-1398.

20. Madhyastha PS, Naik DG, Srikant N, kotian R, Bhat KM. Effect of finishing/polishing techniques and time on surface roughness of silorane and methacrylate based restorative materials. Oral Health Dent Manag. 2015;14(4):212-218.

21. Avsar A, Yuzbasioglu E, Sarac D. The effect of finishing and polishing techniques on the surface roughness and the color of nanocomposite resin restorative materials. Adv Clin Exp Med. 2015;24(5):881-890.

22. Chour RG, Moda A, Arora A, Arafath MY, Shetty VK, Rishal Y. Comparative evaluation; of effect of different polishing systems on surface roughness of composite resin: an in vitro study. J Int Soc Prev Community Dent. 2016;6 (Suppl 2):S166-S170.

23. Cazzaniga G, Ottobelli M, Ionescu A, Garcia-Godoy F, Brambilla E. Surface properties of resin-based composite materials and biofilm formation: a review of the current literature. Am J Dent. 2015;28(6): 311-320.

24. Wolff D, Kraus T, Schach C, et al. Recontouring teeth and closing diastemas with direct composite buildups: a clinical evaluation of survival and quality parameters. J Dent. 2010;38(12):1001-1009.

25. Cardoso MV, de Almeida Neves A, Mine A, et al. Current aspects on bonding effectiveness and stability in adhesive dentistry. Aust Dent $J$. 2011;56 (Suppl 1):31-44.

26. Van Meerbeek B, Yoshihara K, Yoshida Y, Mine A, De Munck J, Van Landuyt KL. State of the art of self-etch adhesives. Dent Mater. 2011; 27(1):17-28.

27. Alhareky M, Tavares M. Amalgam vs composite restoration, survival, and secondary caries. J Evid Based Dent Pract. 2016;16(2): 107-109.

28. Ástvaldsdóttir Á, Dagerhamn J, van Dijken JW, et al. Longevity of posterior resin composite restorations in adults - A systematic review. J Dent. 2015;43(8):934-954.

29. Moura FR, Romano AR, Lund RG, Piva E, Rodrigues Jr SA, Demarco FF. Three-year clinical performance of composite restorations placed by undergraduate dental students. Braz Dent J. 2011;22(2):111-116.

30. Baldissera RA, Corrêa MB, Schuch HS, Collares K, Nascimento GG, Jardim OS. Are there universal restorative composites for anterior and posterior teeth. J Dent. 2013;41(11):1027-1035.

31. Alonso V, Caserio M. A clinical study of direct composite full-coverage crowns: long-term results. Oper Dent. 2012;37(4):432-441.

32. Heintze SD, Rousson V, Hickel R. Clinical effectiveness of direct anterior restorations-a meta-analysis. Dent Mater. 2015;31(5):481-495.

33. Frese C, Schiller P, Staehle HJ, Wolff D. Recontouring teeth and closing diastemas with direct composite buildups: a 5-year follow-up. $J$ Dent. 2013;41(11):979-985.
Clinical, Cosmetic and Investigational Dentistry

\section{Publish your work in this journal}

Clinical, Cosmetic and Investigational Dentistry is an international, peer-reviewed, open access, online journal focusing on the latest clinical and experimental research in dentistry with specific emphasis on cosmetic interventions. Innovative developments in dental materials, techniques and devices that improve outcomes and patient satisfac-

\section{Dovepress}

tion and preference will be highlighted. The manuscript management system is completely online and includes a very quick and fair peerreview system, which is all easy to use. Visit http://www.dovepress. com/testimonials.php to read real quotes from published authors. 